\title{
O LUGAR DA EDUCAÇÃO PROFISSIONAL E TECNOLÓGICA NA REFORMA DO ENSINO MÉDIO EM CONTEXTO BRASILEIRO: DA LEI № 13.145/2017 À BNCC
}

\author{
Dinelise Sousa Santos*, Rivadavia Porto Cavalcante, Jair José Maldaner, Albano Dias Pereira \\ Filho \\ *E-mail: dinelise.santos@ifto.edu.br \\ Instituto Federal de Educação, Ciência e Tecnologia de Tocantins \\ DOI: $10.15628 /$ rbept.2020.9488
}

Artigo submetido em jan/2020 e aceito em mar/2020

\begin{abstract}
RESUMO
Este artigo tem por finalidade discutir o processo histórico-ideológico que subjaz às concepções de educação profissional veiculadas em textos oficiais da política educacional brasileira desta década, concernentes à reforma do ensino médio, aqui representados pela Lei 13.415/17 e a Base Nacional Comum Curricular- BNCC. Buscamos pôr em pauta em que medida as proposições desses documentos reconfiguram o currículo do nível de ensino em questão. Trata-se de uma pesquisa documental e bibliográfica que, em um primeiro momento, buscou a compreensão das políticas para a formação profissional ao longo da história da Educação Profissional e Tecnológica-EPT e sua relação com o mercado de trabalho, com vistas ao entendimento da dicotomia educacional - formação propedêutica versus formação para o trabalho - caracterizada, muitas vezes, no âmbito acadêmico e nas práticas profissionais, como discriminatória e elitista. Para tanto, mediante levantamento bibliográfico e análise documental sobre a atual reformulação do ensino médio, priorizamos a compreensão das possibilidades e do lugar do ensino médio integrado nessa reforma. O resultado do estudo indica que a concepção dualística de educação e de currículo não mudou com o surgimento da Lei 13.415 e com a atual BNCC. Seus princípios sustentam os velhos discursos segregados e dualísticos das políticas educacionais, mostrando-nos o quão desafiador ainda será o papel da EPT no atual contexto brasileiro na formação humana integral.
\end{abstract}

Palavras-Chave: Reforma do ensino médio. BNCC. Formação para o trabalho. Formação humana integral. Educação Profissional e Tecnológica.

\section{THE PLACE OF PROFESSIONAL AND TECHNOLOGICAL EDUCATION IN THE REFORM OF HIGH SCHOOL IN BRAZILIAN CONTEXT: FROM LAW № 13.145 / 2017 TO BNCC}

\begin{abstract}
This article aims to discuss the historical-ideological process that underlies the conceptions of professional education conveyed in official texts of the Brazilian educational policy of this decade, concerning the reform of secondary education, represented here by Law 13.415 / 17 and the National Common Curriculum- BNCC. We seek to discuss the extent to which the propositions of these documents reconfigure the curriculum of the level of education in question. It is a documentary and bibliographic research that, at first, sought to understand the policies for professional training throughout the history of Professional and Technological Education-EPT and its relationship with the labor market, with a view to understanding the educational dichotomy - propaedeutic training versus job training - often characterized in the academic field and in professional practices, as discriminatory and elitist. To this end, through a bibliographic survey and documentary analysis of the current reformulation of high school, we prioritize the
\end{abstract}


understanding of the possibilities and the place of high school integrated in this reform. The result of the study indicates that the dualistic conception of education and curriculum has not changed with the advent of Law 13.415 and the current BNCC. Its principles support the old segregated and dualistic discourses of educational policies, showing us how challenging the role of EPT will still be in the current Brazilian context in integral human formation.

Keywords: High school reform. BNCC. Training for the job. Integral human formation. Professional and Technological Education.

\section{INTRODUÇÃO}

O presente artigo tem como objetivo colocar em pauta a problemática dualística das políticas educacionais para EPT, desde seu surgimento com a criação das Escolas de Aprendizes e Artífices até à reforma do ensino médio, com a lei 13.415/2007, que alterou a lei 9.394/1996 e criou a Base Comum Curricular para o ensino médio, alterando a estrutura do currículo desse nível de ensino.

A motivação para a realização desse estudo se inscreve no reconhecimento de que a unificação das unidades de ensino profissional, conforme a criação da rede de Institutos Federais de Educação Profissional e Tecnológica, por meio da Lei 11.892/2008 de 29 de dezembro de 2008, vem sendo um projeto de educação nacional reservado ao desenvolvimento de conhecimentos gerais, de profissões (o trabalho humano), de ciências e das suas tecnologias, contribuindo na formação politécnica em sentido pleno, entendida aqui, conforme nos aponta Moura (2013, p.707) "como sinônimo de formação humana integral ou omnilateral"

Porém, enquanto política pública de governo, o projeto em questão não está isento da dominação do mercado capitalista que, por sua vez, tem tomado decisões sobre o andamento das políticas educacionais. Devido à crise do capital, correntes neoconservadoras/neoliberais têm forçado o Estado a ceder seu poder social às organizações empresariais, em detrimento de uma formação humana, com vistas a favorecer a fabricação de mão de obra, centrada apenas na realização do trabalho, deixando de fora uma educação para a vida.

Isso posto, este estudo visa contribuir para a superação deste quadro social de divisão de classe no contexto de Educação Profissional no Brasil. Busca-se, mediante um referencial teórico-conceitual, subsídios que auxiliem na resistência e na superação da dicotomia existente entre a formação manual e a intelectual, principalmente no que diz respeito ao ensino médio integrado e do reconhecimento dos Institutos Federais- IF's como espaço e instituição destinada à formação humana em sua integralidade.

Esta pesquisa tem como característica o método de levantamento de fontes bibliográficas centrado na revisão da literatura especializada da área da educação. O foco está direcionado, primeiramente, à trajetória da Educação Profissional e Tecnológica, desde a criação das Escolas de Aprendizes e Artífices à atual configuração da rede de EPT desta década. 
Para proceder o estudo dos referenciais citados e dos documentos oficiais reguladores da EPT, objetos de nossa investigação, apoiamo-nos em ensinamentos de autores filiados à corrente marxiana como Ciavatta (2005), Ramos (2010), Costa e Coutinho (2018), entre outros, além da consulta à legislação vigente que regulamenta a EPT e o ensino médio.

Os documentos em pauta nos conduzem à fundamentação elucidada de que a lei $n^{0} 13.417 / 17$ traz em seu bojo o caráter de conservação indutiva do aspecto dualístico educacional voltado, antes de tudo, para o mercado de trabalho ou para o vestibular, estratificando as perspectivas de uma formação profissional técnica de nível médio voltada para a integralidade do ser em todos os seus aspectos, concepção essa que sempre esteve presente ao longo da história educacional brasileira e profissional, buscando assim, também, a compreensão do espaço da Educação Profissional como formação ao longo do tempo e das expectativas quanto ao seu futuro com a atual reforma do ensino médio.

O artigo está organizado, além de sua introdução, nos seguintes tópicos que se seguem. Primeiramente, refletimos sobre o percurso da EPT, com base no levantamento dos documentos reguladores e orientadores desta modalidade educacional e no referencial teórico constante da literatura especializada do campo da educação brasileira. Em seguida, apresenta-se o direcionamento metodológico do estudo. Na sequência, expõe-se a análise das diretrizes da recente reforma do ensino médio, com vistas a elucidar as possibilidades e o lugar do ensino médio integrado na atual política educacional. Por último, discute-se o resultado seguido de algumas considerações provisórias.

\section{BREVE HISTÓRICO DA EDUCAÇÃO PROFISSIONAL NO BRASIL: FORMAÇÃO HUMANA OU FORMAÇÃO PARA O CAPITAL?}

A Educação Profissional e Tecnológica (EPT) no Brasil teve sua origem na criação das Escolas de Aprendizes e Artífices, por meio do Decreto $\mathrm{n}$ ำ 7.566, de 23 de setembro de 1909, sancionada pelo então presidente Nilo Peçanha, em cada uma das capitais, com o intuito de, como destaca Vieira e Souza Junior (2016, p.156), "formar operários e contramestres, ministrando-se o ensino prático e os conhecimentos técnicos necessários aos menores que pretendessem aprender um ofício", normativa essa balizada pelo fim do trabalho escravo no país e pela criação de fábricas, ancoradas na necessidade que se fazia do "controle social" e, ao mesmo tempo, conforme Costa e Coutinho (2018, p. 1635) da "qualificação da força de trabalho de baixo custo financeiro para a produção fabril e agropecuário da época".

Nessa perspectiva, o ensino técnico no Brasil, de caráter assistencialista, discriminatória e elitista, caracterizou-se, segundo Vieira e Souza Junior (2016, p.156) "como política pública moralizadora da formação do caráter pelo trabalho", destinadas a princípio às crianças de 10 a 13 anos da periferia, como uma forma de não deixá-las "ociosas e evitar que as mesmas se marginalizassem pela falta de não ter o que fazer". Logo depois, a educação 
profissional incorporou jovens e adultos, preservando a mesma essência da "qualificação para o trabalho", firmando-se aqui, de acordo com Costa e Coutinho (2018) como uma educação que se propõe a qualificar para o mercado.

Mesmo diante das dificuldades, esse tipo de ensino se consolidou no país, constituindo-se, tempos depois, nas redes de escolas técnicas, sendo a constituição de 1937 a primeira a falar especificamente da educação profissional:

\begin{abstract}
As escolas pré-vocacionais e profissionais, destinadas às classes menos favorecidas, constituíam dever do Estado, a quem competia, com a colaboração das indústrias e dos sindicatos econômicos, criar, na esfera de sua especialidade, escolas de aprendizes, destinadas aos filhos de seus operários e associados. (BRASIL,1937, s.p.)
\end{abstract}

Ainda no mesmo ano, através da lei no 378, as Escolas de Aprendizes e Artífices foi transformada em Liceus Profissionais.

A partir de 1942, com a Reforma Capanema pelo Decreto-lei $n . .04 .422$, que reformulou o ensino no Brasil e, um ano depois com a criação das leis orgânicas, o dualismo educacional e a divisão social e do trabalho no país só se intensificou ainda mais:

[...] Esse dualismo toma um caráter estrutural especialmente a partir da década de 1940, quando a educação nacional foi organizada por leis orgânicas, segmentando a educação de acordo com os setores produtivos e as profissões, e separando os que deveriam ter o ensino secundário e a formação propedêutica para a universidade e os que deveriam ter formação profissional para a produção.(CIAVATTA,2005, p. 86).

Foi só a partir da promulgação da primeira Lei de Diretrizes e Bases da Educação Brasileira, lei de n. 4.024/1961 que, de forma plena, permitiu-se a equivalência entre 0 ensino secundário e o técnico no prosseguimento de estudos, mas se mostrava contraditória, pois "[...] se por um lado, possibilitava o acesso dos egressos dos cursos profissionalizantes ao nível superior, por outro, o limitava por meio de currículos desprovidos dos conhecimentos e saberes necessários para o ingresso a esse nível de ensino".(Costa e Coutinho, 2018, p.1636).

Com o golpe de 1964, a educação passou por mudanças no ensino de $1^{\circ}$ e $2^{\circ}$ graus, por meio da Lei $\mathrm{n}^{\circ}$ 5.692/71, denominada Lei da profissionalização compulsória, a qual trazia a obrigatoriedade do ensino médio profissional, sofrendo reprovação por parte de alguns:

Não obstante, a resistência de alunos e seus pais à implantação do ensino profissional na escola que tradicionalmente prepara candidatos para o ensino superior, associada a pressões que surgiram da burocracia estatal e das instituições de formação 
profissional, além de empresários do ensino, levaram ao restabelecimento do dualismo estrutural[...]. (FRIGOTTO, CIAVATTA e RAMOS, 2005, p.33).

O discurso para Frigotto, Ciavatta e Ramos (2005) era de formar técnicos por conta da "escassez" destes no mercado e também pela necessidade de oferecer algo para os "frustrados jovens" que não conseguiram ingressar no ensino superior.

Com a retomada da democracia, nos anos 80 , essa lei foi altamente criticada pelos profissionais que se mobilizavam por uma educação que tinha como ideário a politecnia e o fim da dicotomia entre educação básica e técnica, fazendo-se, segundo Ramos (2010) uma crítica ao modelo implantado sob a égide de tal lei, que centravam mais na formação geral que a específica, com conteúdos curriculares de pouca relevância aos estudantes, que por muitas vezes procuravam outras meios quando não conseguiam prosseguir na área de habilitação técnica proferida, sentindo assim, grandes lacunas na sua formação.

Essa obrigatoriedade foi extinta com a promulgação da lei no 7.044/82 e revogação da lei o 5.692/71, mas consoante Costa e Coutinho (2018) permaneceu a dicotomia educacional, consolidando uma cultura discriminatória, apesar de conferirem às escolas técnicas federais um ensino de qualidade, em concordância com Frigotto, Ciavatta e Ramos ( 2005,p. 34) "[...] a marca desse dualismo não estava mais na impossibilidade de aqueles que cursavam o ensino técnico ingressarem, mas sim no plano de valores e dos conteúdos da formação".

A partir de 1996, por meio da Lei de Diretrizes e Bases da Educação, LDB ํo 9.394/1996, o ensino de $2^{\circ}$ grau passou a ser chamado ensino médio, fazendo parte da educação básica, entretanto o ensino profissionalizante foi colocado como parte independente da educação básica e do ensino médio.

No ano seguinte, Fernando Henrique Cardoso, presidente da época, promulgou o decreto 2.208/97, o qual regulamentava a Lei de Diretrizes e Bases da Educação Nacional- LDB, tornando o currículo do ensino profissionalizante parte diversa do ensino médio, podendo ser ofertado só na modalidade subsequente ou concomitante, dando fim na perspectiva de uma lei voltada, de acordo com Ramos (2010) para o rompimento da dicotomia entre a educação básica e técnica, na formação em sua totalidade, integrando ciência, cultura, humanismo e tecnologia, não se pautando pelas necessidades de mercado, mas na construção de possibilidades de futuro e formação ampla e integral para os estudantes.

Esse cenário ainda foi marcado pela criação do Programa de Expansão da Educação Profissional - PROEP, que de acordo com Costa e Coutinho (2018, p.1638) tinha "[...] uma lógica curricular produtivista e privatista para atender aos acordos neoliberais com os organismos internacionais", fortalecendo ainda mais a separação e diferenciação entre a formação propedêutica e a profissional, que com o decreto 9.649/98, desobrigou a união de criar e manter escolas técnicas, agora só era possível com parcerias com estados, municípios, setor produtivo ou organizações não governamentais: 


\begin{abstract}
Desse modo, o Estado se isentaria de obrigatoriedade de manutenção e gestão financeira desses novos estabelecimentos de ensino. Acredita-se que essa foi uma das formas mais cruéis de desacelerar a expansão da EPTNM, bem como possibilitar a educação básica gratuita e de qualidade, com formação humana e profissional às classes marginalizadas e retiradas do centro das sociedades capitalistas. (COSTA e COUTINHO, 2108, p. 1639).
\end{abstract}

Com a revogação do decreto 2.208/1997, veio-se a promulgação do decreto 5.154/2004 pelo então presidente Lula, conhecido pelo seu caráter conciliador, visto para Costa e Coutinho (2018, p. 1639) como uma possibilidade de "(re)integração da educação profissional ao ensino médio, apesar de não ter instinto outras formas de oferta, como a concomitante". Aqui a manutenção das modalidades concomitante e subsequente se deveu, segundo Ramos (2010, p. 51):

\begin{abstract}
A manutenção de formas além da integrada se deveu tanto à necessidade de se construir um consenso com os diversos segmentos da sociedade que ofertam a educação profissional, incluindo as próprias secretarias estaduais de educação, quanto ao reconhecimento da diversidade de necessidades da população jovem e adulta brasileira às quais essas formas poderiam também atender.
\end{abstract}

Frigotto, Ciavatta e Ramos (2005) entendem esse decreto como uma possibilidade de "travessia" para uma nova realidade, onde exista a consolidação da formação básica unitária e politécnica, centrada no princípio educativo do trabalho, contemplados pela ciência e cultura, sendo o ensino médio integrado uma condição "social e histórica" necessária, na tentativa de superação da proposta capitalista de educação.

No ano de 2005 foi criado o Decreto n. -5.622 , de 19 de dezembro de 2005, o qual inseriu a educação a distância como modalidade de ensino na educação profissional, ainda nesse mesmo ano houve a publicação da Lei n.11.195, que permitiu a expansão da oferta de educação profissional com a criação de novas unidades pela União, tendo a mesma os seguintes cursos, conforme o Art. 39, § 2.. , da Lei n.o 11.741/2008, que incorporou o decreto 5.154/ 2004: "I - de formação inicial e continuada ou qualificação profissional; II - de educação profissional técnica de nível médio; III - de educação profissional tecnológica de graduação e pós-graduação (BRASIL, 2008, s.p.)."

Ainda, no ano de 2008, foi criada a lei 11.892, a qual instituiu a Rede Federal de Educação Profissional, Científica e Tecnológica, criando os Institutos Federais de Educação, Ciência e Tecnologia.

Em 2011, foi instituída a Lei n.․ 12.513, por meio do Programa Nacional de Acesso ao Ensino Técnico e Emprego - Pronatec, como forma de ampliação da oferta da educação profissional e tecnológica, alterada pela de n.. 12.816/2013, que também passou a incluir a Bolsa-Formação Estudante. 
Após o agitado impeachment de Dilma Rousseff, em setembro de 2016, o então presidente Michel Temer lançou como primeiro ato de seu governo uma medida provisória, MP(746/2016), que alterou muitos artigos da LDB e, logo depois, incorporou-se à lei 13.415/2017, a tal polêmica "reforma do ensino médio", alvo de muitos protestos e críticas de segmentos que lutam por uma formação humana integrada, já a Base Nacional Comum Curricular (BNCC) para o ensino médio foi homologada em 14 de dezembro de 2018, propondo mudanças para o ensino médio.

No atual governo do presidente Jair Messias Bolsonaro, caracterizado como de extrema direita, apoiado pela classe empresarial e pela elite brasileira, a educação é vista como uma estratégia de manutenção das ideologias capitalistas dominantes, pautadas na formação para o mercado de trabalho, conforme Moura, Lima Filho e Silva (2015) reforçando a divisão social e técnica do trabalho como artifício capitalista, requerendo uma educação classista, de formação "unilateral e mutilada", afastando-se mais uma vez a possibilidade de uma educação formadora de uma sociedade mais justa e igual.

Uma de suas proposituras é a alteração da lei no 11.892/2008 através do projeto de lei no 11.279/2019, que tem como uma de suas propostas a alteração do artigo $7^{\circ}$, o qual se refere como uma das finalidades e características dos institutos federais "ministrar educação profissional técnica de nível médio, prioritariamente na forma de cursos integrados, para os concluintes do ensino fundamental e para o público da educação de jovens e adultos", retirando a partir da nova redação a prioridade da oferta integrada, evidenciando ainda mais que a prioridade de seu governo não contempla a integração da formação geral e profissional, mas o fortalecimento de sua segregação e fragmentação dualística.

É importante considerar, diante do exposto, o quanto os movimentos em prol de uma educação profissional integrada foram de fundamental importância para a EPT no país, principalmente após o decreto 5.154/ 2004 e a lei $11.741 / 2008$ que alteraram a LDB, institucionalizando a educação profissional no Brasil, sendo um avanço para esse tipo de ensino, que a partir de então abriu a possibilidade de integração do ensino médio com o profissional, podendo assim fazer parte da Educação Básica e do quão necessário é seu fortalecimento e resistência perante as novas mudanças no ensino médio, no intuito de não haver um retrocesso histórico.

\section{O LUGAR DA EPT NA REFORMA DO ENSINO MÉDIO: PERSPECTIVAS E POSSIBILIDADES NA LEI 13.415/2017 E NA BNCC.}

Conforme demonstrado nos documentos que regulamentam a recente reforma do currículo do ensino médio e que alteraram o Art. 36 da LDB, observa-se que o currículo dessa etapa educacional vem dividido em duas partes, uma relacionada à BNCC e outra aos itinerários formativos:

Art.36. O currículo do ensino médio será composto pela Base Nacional Comum Curricular e por itinerários formativos, que deverão 
ser organizados por meio da oferta de diferentes arranjos curriculares, conforme a relevância para o contexto local e a possibilidade dos sistemas de ensino, a saber: I - linguagens e suas tecnologias; II matemática e suas tecnologias; III - ciências da natureza e suas tecnologias; IV - ciências humanas e sociais aplicadas; V - formação técnica e profissional (LDB, Art.36; ênfases adicionadas).

Segundo a BNCC (2018) esses arranjos curriculares possibilitam, através da flexibilização curricular, opções de escolhas que podem focar em uma área do conhecimento, na formação técnica e profissional ou, ainda, na integração de diferentes áreas que podem compor um "itinerário integrado". Para Costa e Coutinho (2018, p.1642) "organizar um currículo por itinerários formativos pode incorrer no agrave de limitar o jovem ainda indeciso em escolhas profissionais futuras"

Um primeiro ponto a ser questionado quanto ao que condiz à EPT é que essa integração em diferentes áreas somadas à formação técnica e profissional possibilitada pela BNCC nada tem a ver com o ensino técnico integrado ao ensino médio, que articula formação geral e profissional, nessa nova proposta, a integralização é desarticulada, impedindo, segundo Costa e Coutinho (2018), as possibilidades de superação das dificuldades no conhecimento pelo seu caráter limitador de escolhas por arranjos sem conexão e individualizados, trazendo um grande problema para a EPT quanto às possibilidades e definições de articulação entre o médio e a profissionalização, já que a própria BNCC e a reforma trouxeram o ensino técnico como itinerário no próprio ensino médio.

Quanto ao itinerário formativo "formação técnica e profissional", a resolução CNE/CEB no 3/ 2018, em seu artigo 12, fala-nos sobre sua forma de organização:

\begin{abstract}
V- formação técnica e profissional: desenvolvimento de programas educacionais inovadores e atualizados que promovam efetivamente a qualificação profissional dos estudantes no mundo do trabalho, objetivando sua habilitação profissional tanto para o desenvolvimento de vida e carreira quanto para adaptar-se às novas condições ocupacionais e às exigências do mundo do trabalho contemporâneo e suas contínuas transformações, em condições de competitividade, produtividade e inovação, considerando o contexto local $e$ as possibilidades de oferta pelos sistemas de ensino.(BRASIL, 2018, p.7).
\end{abstract}

Nesse ponto, é importante destacar que o arranjo curricular acima citado não vai de encontro com o que é oferecido nos cursos técnicos de nível médio ofertados pela EPT, de acordo com o Art. $6^{\circ}$, inciso V, da lei 13.415/2017, considerará para essa oferta de formação "a possibilidade de concessão de certificados intermediários de qualificação para o trabalho, quando a formação for estruturada e organizada em etapas com terminalidade" (Brasil 2017b,Art.6,V), podendo ser realizada tanto por cursos técnicos, com cargas horárias de 800 a 1200 horas, como por cursos de qualificação profissionais, com carga horária mínima de $20 \%$ da habilitação proporcionada, podendo o 
arranjo destacado ainda ser ofertado pelo setor privado, sendo também garantido através da Educação a distância(EaD).

No âmbito dessa reforma, esse itinerário poderá substituir a formação básica por cursos curtos de qualificação profissional, tendo mais um contraponto desfavorável à EPT no que diz respeito à carga horária maior oferecida em seus cursos, já que além do propedêutico, ainda se tem o técnico profissionalizante.

Um outro ponto a ser pontuado, quando se compara as áreas de formação da BNCC com os itinerários formativos, vê-se como único itinerário separado de uma área de conhecimento o do técnico e profissionalizante. Revela-se a cristalização, nesse momento, dentro da reforma, da dualidade educacional, numa formação voltada para o mercado de trabalho e para a adaptação de suas novas exigências e transformações contínuas, contrapondo-se aos outros que tem como objetivo a formação para 0 prosseguimento de estudos, numa concepção, de encontro com Silva (2018, p.11) "[...] de formação humana marcada pela intenção de adequação à lógica do mercado e à adaptação à sociedade por meio de uma abstrata noção de cidadania", baseadas em um currículo definido por competências parecidas com o contexto da década de 90, apesar de revigorado, conforme Silva (2018) retoma as mesmas justificativas do velho discurso de adequação da escola às "mudanças do mundo do trabalho", de forma mecanizada e imediatista às inovações tecnológicas e organizacionais.

Um último apontamento a ser discutido diz respeito à docência no que tange à formação técnica e profissional encontrada na BNCC tendo, conforme Costa e Coutinho (2018) duas proposições que contrariam a ideia de uma educação baseada no princípio da politecnia. A primeira, explícita na lei 13.415/ 2017, em seu artigo 16, parágrafo 8 , que dá a oportunidade de ser ofertada em parceria com outras instituições, como o setor privado e o sistema $S^{1}$ de ensino; e uma segunda, que diz respeito a não obrigatoriedade da formação docente em curso superior, de acordo com o que foi acrescentado ao Art. 61 da LDB, que acolhe "[...] os profissionais com notório saber reconhecido pelos respectivos sistemas de ensino, para ministrar conteúdos de áreas afins à sua formação ou experiência profissional, atestados por titulação específica ou prática de ensino em unidades educacionais[...] ( Brasil, 2017b, Art. 61).

No tocante à primeira proposição vale lembrar que essa é bastante parecida, de acordo com Costa e Coutinho (2018) com as parcerias criadas pela reforma Capanema, que criou o Sistema S. Ainda de encontro com os autores:

1 Termo que define o conjunto de organizações das entidades corporativas voltadas para o treinamento profissional, assistência social, consultoria, pesquisa e assistência técnica, que além de terem seu nome iniciado com a letra S, têm raízes comuns e características organizacionais similares. Fazem parte do sistema S: Serviço Nacional de Aprendizagem Industrial (Senai); Serviço Social do Comércio (Sesc); Serviço Social da Indústria (Sesi); e Serviço Nacional de Aprendizagem do Comércio (Senac). Existem ainda os seguintes: Serviço Nacional de Aprendizagem Rural (Senar); Serviço Nacional de Aprendizagem do Cooperativismo (Sescoop); e Serviço Social de Transporte (Sest). Disponível em: https://www12.senado.leg.br/glossário-legislativo/sistema-s. Acesso em: 04 dez. 2019. Fonte: Agência Senado. 
A relação de público/privado pode ser uma conexão que esvaziará as instituições públicas de maiores investimentos em infraestrutura física e humana, dificultando a universalização ou expansão do ensino médio em instituições de ensino público, gratuito e de qualidade. (COSTA E COUTINHO, 2018, p.1647).

A segunda propositura, que se refere ao "notório saber", mostra o agrave de qualquer profissional, mesmo que não tenha o grau de formação adequado, mas que demonstre "saberes" na área, poder lecionar nessa formação de itinerário técnico e profissional, institucionalizando segundo Silva (2018, p.3) "[...] maior precarização do trabalho docente e significa o comprometimento da qualidade da educação profissional", adiando a implementação de políticas que incrementem uma formação de qualidade para os profissionais da educação em EPT.

Apesar da reforma em nada ter alterado sua seção IV-A da LDBEN, que trata da educação profissional técnica de nível médio e suas formas de oferta, ficam aqui alguns questionamentos quanto ao lugar da EPT dentro dessa reforma, do sentido de se manter as formas de articulações, da manutenção do técnico integrado e das semelhanças ou não com a formação técnica e profissional ofertada pela nova lei, além da formação precária dos professores nesse tipo de ensino por meio do "notório saber".

É necessário e de fundamental importância nesse contexto mostrar a diferenciação dos Institutos Federais e dos seus cursos e do que retrata a BNCC, quanto a qualidade sempre ofertada e demonstrada por diversas avaliações institucionais feitas pelo país, a exemplo do Programa Nacional de Avaliação de Estudantes (PISA 2018).

Nos últimos resultados mostrados, os Institutos Federais têm tido os melhores desempenhos do Brasil, conforme o site do "Gazeta do Povo", apesar da média brasileira no exame ter sido ruim comparado aos demais países, "o desempenho médio dos estudantes de 12 institutos federais e de um colégio militar que participaram da avaliação é comparável ao de jovens de nações que figuram entre as 20 melhores classificadas no ranking mundial", lembrando que só uma escola militar foi analisada, ainda conforme o site "as notas dessas escolas estão acima da média dos países integrantes da OCDE (Organização para Cooperação e Desenvolvimento Econômico), que reúne as maiores economias do mundo" e, se analisadas separadamente, "teriam garantido ao Brasil o melhor resultado entre os países da América do Sul que participaram do Pisa 2018".

Evidencia-se, assim, o comprometimento que essas instituições têm tido com uma educação que apesar de não ser voltada a priori para o vestibular, forma cidadãos politécnicos e integrais, tanto para a formação intelectual como profissional, de forma integrada e articulada, pautadas no trabalho como princípio educativo e na cultura e tecnologia como parte de uma formação omnilateral. 


\section{RESULTADOS E DISCUSSÕES}

Mediante análise de documentos oficiais do governo federal, Lei 13.415/2017 e Base Nacional Comum Curricular (BRASIL 2018); e revisão do referencial bibliográfico da EPT, foi possível evidenciar que, após um século de criação da rede de educação/formação profissional no país, as propostas curriculares, neste campo, ainda permanecem presas aos interesses da classe dominante, sustentados pelas políticas públicas do Estado. As asserções postas aqui se sustentam tendo em vista que as contradições ideológicas das políticas de governantes e de seus aliados se valem da educação como política de estratégia alienadora de pessoas e da manutenção das intenções daqueles que detêm o capital (MOURA; LIMA FILHO; SILVA, 2015; SILVA, 2018; COSTA; COUTINHO, 2018). Os valores burgueses e capitalistas ainda estão enraizados no assistencialismo como moeda de troca.

Assim posto, as proposições constantes da BNCC carecem de maiores discussões, de natureza crítica, junto aos profissionais locais (docentes, técnicos administrativos em educação, gestores) acerca das perspectivas e dos impactos educacionais com as recentes diretrizes, principalmente no tocante às particularidades da formulação e da implementação do currículo integrado nos Institutos Federais, com suas características sociais, culturais e necessidades locais específicas, em conformidade com os objetivos dos cursos ofertados no ensino médio daquelas instituições.

$\mathrm{Na}$ reforma do ensino médio, o lugar da educação profissional deveria ser o de articulação com as demais áreas do conhecimento previstas na Lei 13.415 e na BNCC. A continuação da forma integrada, nesta modalidade de ensino, poderia ser igualmente revista pelos profissionais citados, já que a BNCC possibilita a junção do itinerário formativo geral e de formação técnica e profissional, viabilizando a oferta em uma menor duração, revelando-nos, nesse ponto, o quão desafiador será a (re)afirmação de que a formação oferecida nessas instituições tem um valor enorme nas políticas públicas e gratuitas, com ensino de qualidade, que forma tanto para a profissão como para a vida em sociedade.

Quanto à "formação técnica e profissional" constante da BNCC, observase, nesta diretriz, a fragmentação e a desconexão da EPT, enquanto itinerário, dos demais eixos de conhecimentos (conforme evidenciado nos eixos I, II, III e IV do documento), o que confere à educação profissional e tecnológica lugar periférico no documento, fomentando a tradicional perspectiva dualística de formação geral versus formação para o mercado de trabalho, trazendo o velho discurso de preparação mercadológica, instrumental e aligeirada em seu íntimo.

Em contrapartida, os IF's têm mostrado em sua essência a defesa da formação humana integral, omnilateral ou politécnica, não possibilitada ainda de forma efetiva por conta da situação econômica e social do país, mas sendo vista como forma de "travessia" para emancipação humana e cidadã.

Um último quesito a ser debatido é o "notório saber", um outro desafio para a formação profissional, desvendando-se o fortalecimento da formação 
docente e dos programas de complementação pedagógica como alternativa diante do cenário proposto pela reforma.

\section{CONSIDERAÇÕES FINAIS}

A título de conclusão, pode-se destacar alguns pontos relevantes acerca do cenário da educação profissional e tecnológica no Brasil, da sua criação até a contemporaneidade, tendo sempre em torno os embates ideológicos de seus governos por trás, evidenciando-se quase que em sua totalidade a formação dualística entre o intelectual e o manual, respectivamente para a classe dominante e elitizada e, a outra, assistencialista para os pobres e desfavorecidos, vista como ferramenta de alienação dos interesses capitalistas e de mercado.

Evidencia-se também que os ataques à formação integral tem voltado a "pleno vapor" com a nova reforma do ensino médio e com o atual governo, com os mesmos discursos da década de 90, apesar de revigorados, mostrando-se a importância da constante reafirmação do espaço e potencial que a formação profissional oferece à educação brasileira e quão necessária é para a superação das ideologias mercadológicas, como forma de "travessia" para a formação humana integral, omnilateral e politécnica, buscando a construção de uma sociedade mais justa e igual.

É nesse ponto, que o ensino médio integrado é visto como germe para essa perspectiva de futuro que tem sido concretizada desde a criação dos institutos federais, levando-se em conta que para tal "travessia" são necessárias outras modalidades que atendam, no momento, a realidade socioeconômica e educacional do país.

Nesse contexto é crucial o entendimento, conforme Moura (2013) de que a história dual educacional brasileira não é fruto da escola, mas da sociedade em que vivemos, dicotomia imposta pelo modo capitalista de produção.

Assim, é imprescindível que as instituições de ensino, em destaque os Institutos Federais, não esperem pela superação da ideologia burguesa de formação, mas que contribuam para o rompimento da segregação tão discutida, onde "o trabalho e a educação" deixem de ser vistos como partes dissociadas, numa promoção de acesso aos princípios formativos da EPT: ciência, cultura e tecnologia, numa condução para o dimensionamento ontológico, histórico e ético-político, pautado no trabalho como princípio educativo, mostrando, dessa forma, que a EPT tem seu lugar mesmo diante de tantas disputas e contradições. 


\section{REFERÊNCIAS}

Agência

Senado.

Disponível

em:

https://www12.senado.leg.br/noticias/glossario-legislativo/sistema-s. Acesso em :05 dez de 2019.

BRASIL. Constituição dos Estados Unidos do Brasil de 10 de novembro de 1937. Diário Oficial da União. Rio de Janeiro, 10 nov. 1937.Disponível em: http://www.planalto.gov.br/ccivil 03/constituicao/constituicao37.htm. Acesso em: 04 dez. 2019.

BRASIL. Lei o 9.394, de 20 de dezembro de 1996. Estabelece as diretrizes e bases da educação nacional. Diário Oficial da União, Brasília, DF, 23 dez. 1996. Disponível em: http://www.planalto.gov.br/ccivil 03/leis/L9394.htm. Acesso em: 04 dez. 2019.

BRASIL. Lei n.․ 11.195, de 18 de novembro de 2005. Dá nova redação ao § 50 do Art. $3^{\circ}$ da Lei no 8.948, de 8 de dezembro de 1994. Diário Oficial da União. Brasília, 18 nov. 2005. Disponível em: https://www.planalto.gov.br/ ccivil 03/ Ato2004-2006/2005/Lei/L11195.htm. Acesso em: 04 dez. 2019.

BRASIL. Lei $\mathrm{n} .-11.741$, de 16 de julho de 2008. Altera dispositivos da Lei $\mathrm{n}$ 9.394, de 20 de dezembro de 1996, que estabelece as diretrizes e bases da educação nacional, para redimensionar, institucionalizar e integrar as ações da educação profissional técnica de nível médio, da educação de jovens e adultos e da educação profissional e tecnológica. Diário Oficial da União. Brasília, 17 jul. 2008.Disponível em: http://www.planalto.gov.br/ccivil 03/ Ato20072010/2008/Lei/L11741.htm. Acesso em: 09 dez. 2019.

BRASIL. Lei n. 0 11.892, de 29 de dezembro de 2008. Institui a Rede Federal de Educação Profissional, Científica e Tecnológica, cria os Institutos Federais de Educação, Ciência e Tecnologia, e dá outras providências. Diário Oficial da União. Brasília, 30 dez. 2008.Disponível em:http://www.planalto.gov.br/ccivil 03/ Ato2007-2010/2008/Lei/L11892.htm.

Acesso em: 04 dez. 2019.

BRASIL. Lei no 13.415, de 16 de fevereiro de 2017. Altera as Leis $n^{0}$ 9.394, de 20 de dezembro de 1996, que estabelece as diretrizes e bases da educação nacional, e 11.494, de 20 de junho 2007, que regulamenta o Fundo de Manutenção e Desenvolvimento da Educação Básica e de Valorização dos Profissionais da Educação, a Consolidação das Leis do Trabalho - CLT, aprovada pelo Decreto-Lei no 5.452, de 1o de maio de 1943, e o Decreto-Lei no 236, de 28 de fevereiro de 1967; revoga a Lei no 11.161, de 5 de agosto de 2005; e institui a Política de Fomento à Implementação de Escolas de Ensino Médio em Tempo Integral. Diário Oficial da União, Brasília, 17 de fevereiro de 2017. Disponível em: http://www.planalto.gov.br/ccivil 03/ Ato20152018/2017/Lei/L13415.htm. Acesso em: 04 dez. 2019.

BRASIL. Conselho Nacional de Educação; Câmara de Educação Básica. Resolução no 3, de 21 de novembro de 2018. Atualiza as Diretrizes Curriculares Nacionais para o Ensino Médio. Diário Oficial da União, Brasília, 22 de novembro de 2018, Seção 1, p. 21. Disponível em: 
http://novoensinomedio.mec.gov.br/resources/downloads/pdf/dcnem.pdf. Acesso em: 04 dez. 2019.

BRASIL. Ministério da Educação. Base Nacional Comum Curricular. Brasília: MEC, 2018. Disponível em: http://basenacionalcomum.mec.gov.br/images/BNC C 20dez site.pdf. Acesso em: 04 de dezembro de 2019.

CIAVATTA, Maria; A formação integrada: a escola e o trabalho como lugares de memória e de identidade. p. 83 a 105. São Paulo: Cortez, 2005.

COSTA, Maria Adélia; COUTINHO, Eduardo Henrique Lacerda. Educação Profissional e Reforma do Ensino Médio: lei oㅜ 13.415 / 2017. Educ. Real. Porto Alegre, v. 43, n. 4, p. 1633-1652, outubro de 2018. Disponível em:

<http://www.scielo.br/scielo.php?script=sci arttext\&pid=S2175-

62362018000401633\&lng=en\&nrm=iso>. acesso em 04 dez. 2019.

FRIGOTTO, Gaudêncio; CIAVATTA, Maria; RAMOS, Marise (orgs.). Ensino médio integrado: concepção e contradições. São Paulo: Cortez, 2005.

Gazeta do Povo, 03 de dez. 2019. Disponível em: https://www.gazetadopovo.com.br/educacao/escolas-federais-particulares-emilitares-entre-as-melhores-do-mundo-no-pisa. Acesso em :04 dez de 2019.

MOURA, Dante Henrique. Ensino médio integrado: subsunção aos interesses do capital ou travessia para a formação humana integral? Educ. Pesqui., São Paulo, v. 39, n.3, p. 705-720, jul./ set. 2013.

MOURA, Dante Henrique; LIMA FILHO, Domingos Leite; SILVA, Mônica Ribeiro. Politecnia e formação integrada: confrontos conceituais, projetos políticos e contradições históricas da educação brasileira. Revista Brasileira de Educação, v. 20, n. 63, p. 1057-1080, 2015.

RAMOS, Marise. Ensino Médio Integrado: ciência, trabalho e cultura na relação entre educação profissional e educação básica. In MOLL, Jaqueline et al. Educação profissional e tecnológica no Brasil contemporâneo: desafios, tensões e possibilidades. Porto Alegre: Artmed, 2010. Cap. 2 p. 42 a 58.

SILVA, Monica Ribeiro da. A BNCC da Reforma do Ensino Médio: O resgate de um empoeirado discurso. Educ. rev., Belo Horizonte, v. 34, e214130, 2018. Disponível em: <http://www.scielo.br/scielo.php?script=sci arttext\&pid=S010246982018000100301\&lng=en\&nrm=iso> . Acesso em 05 Dez. 2019.

VIEIRA, Albani Marisa Dudeque Pianovski; SOUZA JUNIOR, Antonio de. A Educação Profissional no Brasil. Revista Interacções, n 40, p. 152-169, 2016. 